repetition of organic and inorganic deposits, of the carboniferous formation, and the remarkable crust movements which enabled them to accumulate, are without subsequent examples.

In conclusion, I must remind you that the volumes of the "Geological Record" give the literature of the carboniferous formation year by year, and that lately a magnificent contribution to the subject has appeared in the memoirs of the Geological Survey of England and Wales in the form of a great volume on the geology of the Yorkshire coal fields, by Prcf. Green, one of our vice-presidents, and Mr. Russell. A very concise and excellent geology of the West Riding has also recently been published by Mr. Davis, who is amongst us to-day, and Mr. Bauermann has contributed a capital article on coal to the "Encyclopredia Rritannica."

\section{THE FRENCH ASSOCIATION}

\section{Montpellier, Sunday}

THE French Association for the Advancement of Science met at Montpellier on August 28. The president this year is M. Bardoux, the late Minister for Public Instruction, who has been succeeded by M. Ferry.

His address was devoted entirely to generalities on the neces sity of providing a good education for the young. He did not touch upon the great question which agitates the public mind in France in connection with the Ferry Bill. It may be inferred from the strong encomiums passed on M. Jules Simon, that $M$. Bardoux must be ranked among the opponents to the Ferry Bill

M. Laissac, mayor of Montpellier, and $M$. Cazelle, prefect of the Herault, replied to $M$. Bardoux. M. Saporta, the general secretary, gave an address summarising the results of the last year's meeting, and $M$. Georges Masson read a financia statement which showed that the capital of the Society amounts to about 300,000 francs. The subsidies paid for research last year amounted to ro, 000 francs.

These addresses being the only ones which were given in the name of the Association, and as the presidents of sections gave no official addresses, it will be quite impossible to have any idea of the opinions of the meeting on the topics of the day.

Although but a small city, Montpellier is famous in the annals of science, and in former years its university was deemed a rival to Paris. But in latter years Montpellier has lost much of its prestige, although it had the honour to be the birthplace of Auguste Comte. The growing academy of Toulouse disputes with Montpellier the pre-eminence in south-eastern France. Meanwhile the impending meeting of savants at Perpignan on the occasion of the inauguration of Arago's statue at the end of September will throw the Montpellier meeting somewhat into the shade, and deprive it of a number of constant and influential members. The interest of the meeting will consist principally in excursions professing to promote ends of great moment for the welfare of the region, viz., the extinction of phylloxera, the construction of an irrigation canal from the Rhone, the local meteorology and botany, which are strongly represented by M. Charles Martius, a brilliant writer, and the director of the celebrated Montpellier plant-gardens. A specimen of the French Atlantic cable now in course of being placed, will be exhibited and explained by $M$. Gariel, the general secretary of the Council, and the scheme of the French Company explained for the first time. Experiments will be made on electric lighting and the telephone.

The French scientific caravan, officered by MM. Quatrefages, Mortillet, and Broca, to be sent to the Congress of Anthropology at Moscow, is to arrive in Montpellier before the end of the meeting. M. Bergeron, one of the French savants, who was present at the Sheffield meeting, has arrived in order to tell the French Association of what was done by her elder sister.

\section{THE SWISS NATURALISTS}

PHE sixty-second annual meeting of the Swiss naturalists was opened on July ro at St. Gall. The attendance was comparatively large, no less than two hundred Swiss and twenty-one foreign savants being present. Among the latter we notice Prof. Hébert (Paris), Mr. Forrer (San Francisco), Herr Nördlinger (Stuttgart), Dr. Richthofen, and many others.

On Monday, the $x$ th, the first public meeting was opened at the Grossrathhaus, before a large audience of visitors and ladies, by Dr. Rechsteiner (St. Gall), who gave an address on the recent progress of science; also pointing out the importance of the neighbourhood of St. Gall for the study of geology, and discussing the variety and importance of chemical processes in the life of nature. A second lecture was given by Prof. C. Vogt (Geneva) on the archropteryx, the interesting reptile-bird which has provoked so animated a discussion among anatomists, and of which we possess only two specimens-that of the British Mnseum and that newly discovered at Solenhofen, Germany. According to the first, which was very incomplete, this Jurassic animal was considered as a bird, having a beak, nails, and feathers; while the Solenhofen specimen, quite complete, and of which Prof. Vogt exhibited very good photographs, proves undoubtedly that we have to do with a bird-like reptile of the size of a pigeon, which had both scales and feathers, a beak provided with teeth, armed wings, bird-like feet with nails, and a reptile tail consisting of twenty vertebræ. This discovery gave to Prof. Vogt the occasion to make a brilliant address on the origin of species, the adaptation of organisms to the medium they inhabit, and the way in which this adaptation goes on from the periphery to the centre.

Two other lectures were given by M. Victor Fatio, on the phylloxera, and by M. Raoul Pictet on the synthetical theory of calorific phenomena. The naturalists then went to the traditional breakfast served on paper table-cloths with paper naplins, in the beautiful ball of the Kornhalle, the walls of which are decorated with four pictures, by M. Kirchofer, which represent the country of St. Gall during the periods of the lignite (Schieferkohle), of the molasse, of the glacial epoch, and of prehistoric man. At two began the sittings of the sections. In the Section of Physics Prof. Hagenbach opened a very interesting philosophical discussion on "centrifugal force," in which discussion he was followed by Prof. Mousson (Zuiich), who made a valuable communication on the structure of solid bodies, and on the molecular phenomena which produce the phenomenon of heat. Prof. Pictet (Geneva) explained his researches into the mechanical theory of heat. On the following day Professors Forel (Morges) and L. Soret (Geneva), the indefatigable students of the oscillations of the level of the Lake of Geneva, gave, in the Section of Physics, very interesting communications on that subject, and especially on the rhythmical oscillations described as seiches.-M. Dufour having communicated the results of his measurements on the glacier of the Rhone, according to which the lower extremity of this glacier has receded no less than eighty metres (260 feet) during the last two years, a long discussion on the causes of the oscillations of glaciers was engaged between MM. Dufour, Forel, Mousson, and Hagenbach. Finally we notice in the Section of Physics the communications, by M. H. Dufour, on the diffusion of gases; by Prof. Hagenbach on the forms of hail; and by Prof. Colladon (Geneva) on his theories on the optical properties of ice.

The sixty-third meeting will take place next year at Brieg, in the Valley of the Rhone.

\section{SCIENTIFIC SERIALS}

The Journal of Physiology (vol. ii. No. 2, issued July).- On the effect of the respiratory movements on the pulmonary circulation, by H. P. Bowditch and G. M. Garland.-On absorption without circulation, by B. F. Lautenbach.-On protagon, by Arthur Gamgee and Ernst Blankenhorn.-On a few further experiments with pituria, by Sydney Ringer and William Murrell. - On the antagonism between pilocarpine and extract of Amonito muscaria, by Sydney Ringer and William Murrell.-On some old and new experiments on the fibrin-ferment, by Arthur Gamgee. - On the effect of two succeeding stimuli upon muscular contrac. tion, by Henry Sewall.- There is added a list of titles of books and papers of physiological interest published since Decemb:r 3 I, 1878 , to date.

Fournal of the Royal Microscopical Sosiety (August). - Trans. actions.- - On a new species of excavating sponge (Alectona mil. lari), and on a new species of Raphidotheca $(\vec{R}$, affinis $)$, by $\mathrm{H}$. J. Carter, F.R.S.-On a new genus and species of foraminifera (Aphrosina informis), and on the spicules of an unknown sponge, by H. J. Carter, F.R.S. - On the theory of illuminating apparatus employed with the microscope, by Dr. H. E. Fripp.-Ob. servations on Notommata Werneckii and its parasitism in the tubes of Vaucheria, by Prof. Balbiani ; translated from the $A n$ nales des Sciences Naturelles (Zoologie), 1878.-The record of current researches relating to invertebrata, cryptogamia, nicroscopy, \&c. 
The American Naturalist (Angust). - Adjectives of colour in Indian languages, by Albert S. Gatschet.-On the habits of a species of tarantula (T. tigrina?), by Mrs. Mary Treat.-On species of tarantula (Tape Cod, by Warren Upham.-The geological museum of the School of Mines, Columbia College, by Israël C. Russell.

Kosmos, iii. Heft 3, June; Th. Buy, on the estimating of conflicting anthorities, or thoughts on the education of the future.-Dr. Otto Kuntze, how the primitive rocks are builtup.-Dr. Dodel-Port, Infusoria as assisting in the fructification in the Floridex, being a contribution to our knowledge of the interchange of relations between the plant and animal worlds, with illustrations.-Dr. D. F. Weinland, on the statistics of population in the animal lingdom. -T. $H$. Becker, on the serpent myth.

THE Revue Internationale des Sciences (August) contains the following papers :- On the embryogenous vesicle and on parthenogenesis in animals, by Prof. Balbiani.-On the metaphysics of Claude Bernard, by Ch. Letourneau.-On the history of embryological doctrines, by Prof. Kölliker. This is the recapitu. lation of a German work by the eminent biologist, recently published in a French translation.-On the reality of our perceptions, by Prof. Helmholtz.

\section{SOCIETIES AND ACADEMIES PARIS}

Academy of Sciences, August 18.-M. Daubrée in the chair. - The following papers were read:-On the meridian observations of the minor planets, made at Greenwich and Paris during the second quarter of 1879 , by M. Mouchez.-Mr. J. A. Serret presented to the Academy the eighth volume of the works of Lagrange, entitled "'Traité de la Resolution des Equations numériques de tous les Degrés, avec des Notes sur plusieurs Points de la Théorie des Equations algébriques."-M. MilneEdwards presented the complement of the thirteenth volume of his "Leçons sur la Physiologie et l'Anatomie comparées de l'Homme et des Animaux."-Reply by M. Berthelot to $M$. Wurtz's observations on hydrate of chloral. - On the phenomena of secreting irritation which are apparent in rabbits under the influence of faradisation of the tympanum, by MM. Vulpian and Journiac.-Table of numbers of invariant derivatives of given order and degree, belonging to the binary form of the second order, by Prof. Sylvester.Methods of graphic calculus; employment of these methods for the revision of projects bearing on the development of the network of French railways, by M. L. Lalanne.-On irrigations and the sulphide of carbon, by $M$. Mabègue.-On the submersion of vines as a remedy against phylloxera, by $M$. Faucon.-M. Davin made a communication on the ssme subject.-The President then stated to the meeting that M. Janssen had been designated to represent the Academy at the inauguration of the statue of François Arago at Perpignan.The second volume of the "Correspondance politique de Fréderic le Grand" was presented to the Academy by the Berlin Academy of Sciences.-On the integration of irrationals of the second degree, by M. Alexéeff.-Observations on $M$. Aoust's note on the movement of a straight line in a plane, by M. Ed. Habich.-On atmospheric waves and the monthly lunar equation, by $M$. Bouquet de la Grye.-On the scintillation of coal-gas flames, by M. F. A. Forel.-On the absorption of nitric oxide by the proto-salts of iron.-On the reaction of chloride of zinc on normal butylic alcohol, by MM. Le Bel and Greene.-Thermal researches on nitroglycerine, by M. H. Boutmy.-On the tenor of urea in urines, by M. G. Esbach.-On the elimination of bromine from bromocitraconic acid, and on a new organic acid, by M. E. Bourgoin.-On scandium, by M. P. Clève.-On the oxy-acids of sulphur, by M. Maumené.-On the composition of slate, by the same,- Note on a means of preventing inundations, by $M$. A. Sarrand.-On a peculiarity apparent in Jupiter and its satellites, by M. E. Gand.

August 25.-M. Daubrée in the chair.-The following papers were read:-Discovery of two comets, communicated by $M$. Mouchez, One was discovered by M. Palisa, of Pola, and the other by $M$. Hartwig, of Strassburg.--On the digestive ferment of Carica papaya, by MM. Wurtz and Bouchut. This strong ferment (papaine) is easily isolated.-Reply to M. Berthelot's observations, by M. Wurtz.-On a process by which may be obtained in any ball-governor, the degree of isochronism desired, and maintaining this degree for all speeds; general theory, by M. Léauté.-On some multiple stars, according to observations made at the Imperial Observatory of Rio de Janeiro, by $\mathbf{M}$. Cruls.-Researches on the compressibility of gases at high pressures, ky M. Amagat. All the gases studied, except hydrogen, presented a minimum of the product $p v$, situated for each gas about the following pressures (expressed in metres of mercury): nitrogen $50 \mathrm{~m}$, oxygen 100 , air 65 , carbonic oxide 50 , formene 120, and ethylene 65. Thus, as might be expected, the gases that are probably nearest the circumstances determining their liquefaction are those which attain the greatest compressibility.On the naximum tension and the vapour density of alizarine, by M. Troost. The maximum tension is about $x \mathrm{~m} \mathrm{~mm}$. at $26 \mathrm{r}^{\circ}$ and $20 \mathrm{~mm}$. at $276^{\circ}$. The observed density was, in three experi-

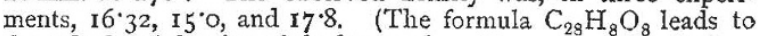
the calculated density 16.62 for 4 vols. The equivalent of alizarine, then, corresponds to 4 vols.).--Purification of hydrogen, by M. Lionet. This may be effected in the cold state. Oxide of copper arrests, in cold, all the combinations of hydrogen which it may contain as impurities, except carbonised hydrogens.-On the active principle of Ammi visnaga, by M. Mustapha.- On a new mode of administration of ether, chloroform, or chloral to the sensitive plant; application to determining the velocity of liquids in the organs of this plant, by M. Arloing. The mode is that of presenting the anrsthetic to be absorbed by the roots. Chloral does not act as an anæsthetic on the sensitive plant; the other two have a similar action to that on animals whether they penetrate by the leaves or the roots. The petioles fall suddenly and successively from below upwards as chloroform absorbed by the roots reaches their insertion. Hence the rate of absorption can be easily calculated. The velocity increases from the base to the top and is one and a half times to twice as great in the petioles as in the stem.-Studies on hydrophobia, by M. Galtier. This relates chiefly on its manifestation in the rabbit, to which it may be transmitted, causing paralysis and convulsions. Salicylic acid administered by hypodermic injection daily did nof prevent development of the disorder in the rabbit. The saliva of a mad dog, obtained from the living animal and preserved in water, is virulent, in some cases, even twenty-four hours afterwards.- Researches on animal heat, by M. D'Arsonval. Calorimetry should, scientifically, precede thermometry. The author proposes a new calorimetric method, by which the production of heat in animals can be followed during whole days and weeks. The calorimeter is in an inclosure at constant temperature; and it regulates automatically its own temperature, which remains always invariable.-Researches on the rôle of nerve fibres contained in the anastomosis between the superior laryngeal nerve and the recurrent laryngeal nerve, by $\mathrm{M}$. François Franck.-On the malacodermic zoantharia of the coast of Marseilles, by M. Jourdan.-Diffusion of copper in primordial rocks and sedimentary deposits proceeding from them; consequences, by $\mathbf{M}$. Dieulafait. - The falling stars of August, 1879 , by M. Chapelas,

\section{CONTENTS}

PAGR

The Heman Species. By W. L. Dista.t . . . . . . . 429

LETTERS TO THE EDITOR:-

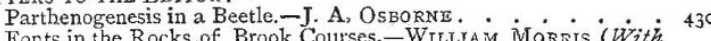

Fonts in the Rocks of Brook Courses.-WILIAAM MoRRIs (With Diagrams)

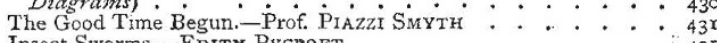

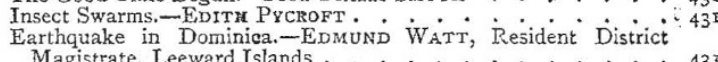
Magistrate, Leeward Islands

Is it True that no Animal can be shown to have made Use of Antecedent Experience to intentionally improve upon the Past? J. E. S.

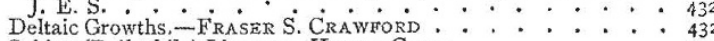

Sphinx (Deilephila) Lineata.-Henry Cecil . . . . . . . . 432 The Recent Hail-storm.-CHAS. FREDK. WHITE : . . : : 432 OUR ASTRONOMICAL COLUMN:-

The Washington Catalogue . . . . . . . . . . . . . 432

New Comets . By Rear-Admiral Jorn RodGers : : : : 433

Grographical Notes . . . . . . . 433

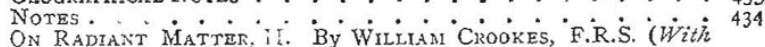
Illustrotions)

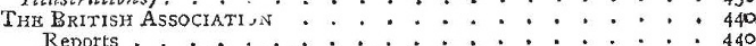

Section A-Rathematical and Physical

Section A-Geology-Oening Address by Prof. $\dot{P}$. Martin Duncan 44 F.R.S., Vice-President of the Geological Society, President of the Section . . . . . . . . . . . 448 THE FRENCH ASSOCIATION

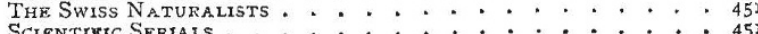

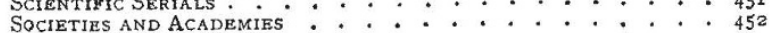

